Synthesis of Natural

Products and

Potential Drugs

\section{Syntheses of Hapalindole-Type Alkaloids}<smiles>O=CCc1cn(S(=O)(=O)c2ccccc2)c2ccccc12</smiles>

1. B, $\mathrm{NH}_{3}, 4 \AA \mathrm{MS}$, EtOH $-78{ }^{\circ} \mathrm{C}$ to r.t.

2. $\mathrm{Mg}, \mathrm{NH}_{4} \mathrm{Cl}, \mathrm{MeOH}$

3. C, $\mathrm{CH}_{2} \mathrm{Cl}_{2}$

$47 \%$
D

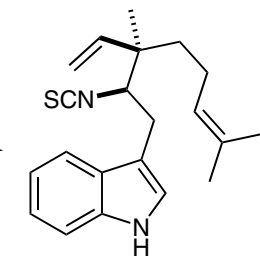

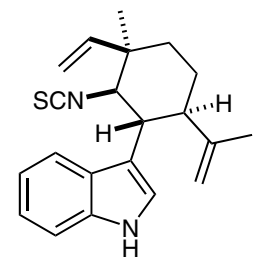

Hapalindole Q single isomer

\section{Key words}

hapalindole alkaloids

bioinspired synthesis

aza-Prins cyclization

\section{SYNFACTen} oxidative aza-Prins cyclization<smiles>CC(C)=CCCC(C)=CC[18OH]</smiles>

Significance: Members of the hapalindole alkaIoid family have attracted considerable attention from the synthetic community due to their intriguing molecular architectures. In 1994, Moore et al. proposed that the biosynthesis of these alkaloids involves a cationic cyclization sequence to form the highly substituted cyclohexane. Inspired by this hypothesis, Li and co-workers report their successful implementation of such a strategy to access several hapalindole-type natural products.
Comment: Cyclization precursor $\mathbf{D}$ was obtained by a three-step sequence from indole $\mathbf{A}$ by allylation of an in situ generated imine. When $\mathbf{D}$ was subjected to oxidative conditions under Lewis acid activation with scandium(III) triflate, an oxidative aza-Prins cyclization yielded hapalindole Q in 48\% yield as the only isomer. Similarly, five other naturally occurring alkaloids of this family were synthesized by application of this elegant strategy. 